methods where very small level differences can be more easily and accurately measured; some 15 pages have therefore been added to the first edition covering such topics as atomic beam resonance and optical pumping. As might be expected from the author's interests, the sections on width and shape of spectral lines have also been increased with a discussion on Voigt profiles following recent work. Recent developments in the field of auto-ionization have also been included. Basically the book remains as in the 1962 edition-an excellent summary of the theoretical interpretation of atomic spectra, with hyperfine structure and isotope shift being most thoroughly treated. The omission of even a passing mention of applied spectroscopy, either in the spectrochemical aspects or its use in astrophysics, for example, solar eorona and ultraviolet spectra (see the work on the solar eclipse described in Nature, 226, 229 and 1097; 1970), emphasizes the academic outlook. The book will continue to prove most useful for the more advanced undergraduate and the research worker both in the title subject itself and related fields where interpretation of spectra is essential.

L. Bovey

\section{AIR POLLUTION MEASUREMENT}

\section{The Analysis of Air Pollutants}

By W. Leithe. Translated by $\mathrm{R}$. Kondor. Pp. $\mathrm{x}+304$. (Ann Arbor-Humphrey: Ann Arbor and London, July 1970.) \$18.75.

THIs book is a translation of the original German edition of 1968. In this English edition is included the author's addenda (11 pp.) giving additions and bibliographic references which apply in particular to British and American conditions.

The book is divided into six parts. The first is a discussion on the problems of clean air. History and legislation are considered as well as sources and control of pollution, meteorological effects on dispersion and the hygiene of air pollutants. In the space available these aspects can be but briefly summarized. Regulations operative in German-speaking countries predominate and proposed values of maximum ground level concentrations. are the MIK-values of the Union of German Engineers. The addenda relating British legislation is disappointing. The work of the Alkali Inspectorate is noted and the Clean Air Act (1956) is briefly-and incorrectly-summarized in six lines. More recent legislation is not mentioned.

The next two parts deal with special techniques for air sampling and for preparation of gaseous mixtures of known composition. These are most useful sections, the techniques being most clearly described. The fourth part considers special analytical methods. A selection of apparatus specifically designed for estimation of pollutants, from the simple Dräger tubes to sophisticated automatic continuous devices of British, American and German manufacture, is described. The generous treatment of gas chromatographic methods of pollution measurement is particularly interesting.

The last two parts (which account for more than 50 per cent of the book) contain a selection of methods for the estimation of all types of pollutants. The working procedures are described with typical Germanic thoroughness and attention to detail. All methods are supported by an extensive bibliography. (The bibliography contains 327 entries and an additional 88 references are listed in the addenda.) It is disappointing that the Warren Spring method for the estimation of smoke-as used in the British National Survey--is omitted but, in any selection, one expects to find certain personal favourites excluded.

Overall, the work should prove to be a vade mecum for the analyst engaged in any aspect of pollution measurement.

\section{Shorl Notices}

World Nuclear Directory. Fourth edition. Pp. lxxix + 764. (Harrap: London, November 1970.) 300s.

THE latest edition of this comprehensive reference book remains basically an international list by countries of bodies concerned with the study and exploitation of nuclear phenomena. The entries under the name of a particular country are divided into subgroups such as national agencies, government departments, universities and industrial concerns; each entry gives as short account of the nuclear activities of the body or institution with its address and the names of its chief personnel (in most cases). One of the principal additions is a list of reactors throughout the world, with their commonly used abbreviations or names and their state (under construction, proposed or dismantled, for example). A list of world nuclear periodicals and their editors or editorial boards is also included. The book can be slightly criticized on the grounds that the subgroups run on from one to the next without distinction. It is possible that a reader unfamiliar with the layout and not using the index might look in the wrong subgroup because each is listed alphabetically.

X-rays. By Brian Bowers. (A Science Museum Booklet.) Pp. 36. (HMSO: London, 1970.) $4 s 6 d$.

THIs booklet is primarily a history of the development of $X$-rays and an account of their everyday use in such diverse applications as medicine, materials testing and the study of painting. As a Science Museum booklet, it begins predictably enough with a brief survey of the museum's own collection of X-ray equipment and early radiographs. The booklet commends itself to sixth formers and to students about to visit the museum, and indeed to anybody, specialist or not, interested in an overall picture of the growth of the subject. One unusual feature of the publication is a description of popular attitudes to $\mathrm{X}$-rays soon after their discovery at the end of the last century; a New York newspaper, for example, announced that X-rays were being used "to reflect anatomic dia. grams directly into the brains of the students, making a much more enduring impression than the ordinary methods of learning anatomic details".

Non-Solar X- and Gamma-ray Astronomy. Edited by L. Gratton. (International Astronomical Union Symposium No. 37, Rome, Italy, May 8-10, 1969.) Pp. $x+425$. (Reidel: Dordrecht, 1970.) Hfl. 70.

OVER the past eight years high energy astronomy has become an important source of information about the universe. The expected launch in 1971 of a satellite devoted exclusively to high energy astronomy should, if successful, provide more information each day than has so far been gleaned by all the balloon and sounding rocket experiments. This, then, is a good time to take stock of the situation in high energy astronomy. The symposium held in Rome in 1969 achieved just such a stocktaking, and the publication of its proceedings provides a landmark in the development of the topic. Observations are, in general, not yet sufficiently definitive for detailed theories of the sources to be constructed, but reviews of the theoretical position as of 1969 are very complete, so that anybody working in the field of high energy astronomy would need little more than this volume and those papers published since mid 1969 in order to place his own work in perspective. When so much has already been achieved with limited techniques the potential of the X-ray Explorer satellite is aweinspiring; this may well be the last opportunity for any normal individual to have any hope of achieving a widespread knowledge of the whole field. 